\title{
Cytogenetic Diagnosis and Analysis of the Clinical Profile of Individuals with Non-down Syndrome Intellectual Disability
}

Fantin, C. ${ }^{1}$, Prazeres, V. G. M. ${ }^{2}$, Benzaquem, D. C. ${ }^{1}$, Fernandes, E. R. Q. G. S. ${ }^{3}$, Oliveira, D. P. ${ }^{3}$ and Ribeiro-Lima, J. C. ${ }^{1}$

1. Laboratório de Proteômica e Genômica, Departamento de Genética Molecular e Citogenética, Escola Superior de Ciências da Saúde, Universidade do Estado do Amazonas, Manaus 69065-001, Brasil

2. Departamento de Saúde Materno Infantil, Universidade Federal do Amazonas, Manaus 69076-005, Brasil

3.Unidade de Laboratório de Análises Clínicas, Setor de Citogenética, Hospital Universitário Getúlio Vargas, Universidade Federal do Amazonas, Manaus 69076-005, Brasil

\begin{abstract}
Chromosomal alterations are the main causes of genetic diseases. One of the characteristics of certain genetic syndromes is ID (intellectual disability) presented by the individual in varying degrees. The study of the ID, its etiology, association or not with chromosomal abnormalities and a clinical diagnosis associated with the examination of karyotype are important aspects to consider when providing genetic counseling for families. Due to the lack of similar studies and of easy access to cytogenetic services for the Amazonian population, this study aimed to contribute to the advancement of this line of study in the state, analyzing the karyotype of individuals with ID, not Down Syndrome treated at the APAE-Manaus and identifying the main types of chromosomal alterations in the individuals analyzed. Analyzes were performed of the clinical diagnosis through investigation of the data from the interview and medical records as well as analysis of the karyotype of 31 patients with non-Down syndrome ID, attended in the APAE-Manaus. Of these subjects, 20 were female and 11 male. The results showed only 2 cases of chromosome abnormalities are detectable by classical cytogenetics, one of mosaic Turner syndrome and one a heterochromatic variant. It is therefore necessary to complement the study with the addition of molecular techniques for the investigation of microdeletions and/or other alterations not detectable through the banding technique, mainly for individuals whose dysmorphisms indicate a suspected syndrome.
\end{abstract}

Key words: Intellectual disability, classical cytogenetics, G banding.

\section{Introduction}

The American Association on Intellectual and Developmental Disabilities [1] defines ID (intellectual disability) as the lower intellectual functioning or IQ (intelligence quotient) than the populational mean associated with adaptive limitations in at least two areas of skills, such as communication, self-care, home life, social adaptation, health and safety, use of community resources, determination, academic functions, leisure and work. Intellectual disability is also considered an incomplete or inhibited state of

Corresponding author: Cleiton Fantin, Ph.D., professor, research fields: genetics and cytogenetics. development of the intellect, occurring in about 1-3\% of the population, causing impairment in cognitive, linguistic, motor and social components of the intelligence of the individual [2]. In the World Health Organization WHO-CID 10 [3], the definition of ID is based on quantitative criteria for classification and, according to the result obtained in IQ tests, it can be classified as mild, moderate, severe, and profound. The diagnosis of ID is performed by doctors and psychologists, however, interdisciplinary teams of educational institutions can also carry it out according to the demand and institutional scope in which the individual is inserted [4]. 
Syndromic ID presents an association with phenotypes of malformations, dysmorphism, seizures, etc., whereas in non-syndromic ID the only clinical manifestation of the patient is the ID. In cases of syndromic ID the presence of other associated signs and symptoms allow the patient to be clinically categorized into a known genetic syndrome, usually these are the more severe cases [5]. However, about $20-50 \%$ of the moderate to severe cases and $80 \%$ of the mild cases of ID do not have a genetic diagnosis [4].

The etiology of ID is difficult because it can either be caused by environmental factors, such as perinatal cerebral ischemia, fetal alcohol syndrome, pre- or post-natal infection, or by genetic factors, such as chromosomal and single gene disorders, that is, there are multiple factors that may be related to ID independent of social class or status. This justifies the need for inclusion of ID as a diagnostic category, as this would help in the identification, intervention, support, promotion of care and attendance to rights positively contributing to the quality of life of the patient and family [4-6].

Cytogenetic studies have contributed to the diagnosis of diseases related to chromosomal abnormalities and their relationship with intellectual disabilities. Cytogenetic techniques used in the etiological evaluation of ID are important tools in the analysis and diagnosis of affected individuals, enabling early therapeutic interventions. When a diagnosis is confirmed, doubts and questions of parents can be clarified and reproductive decisions are taken considering the definite diagnosis in cases of genetic counseling [7].

In Special Education Schools in Santiago, Chile, Alliende et al. [8] conducted a study including 103 individuals with non-Down syndrome ID, of whom only one had an etiologic diagnosis. In another study by Abreu [9], carried out in three APAES of the Rio Preto region of São Paulo, 12.1\% of individuals affected by ID had chromosomal abnormalities, of which $90.2 \%$ were numerical, mostly trisomy 21 . In a study conducted by Storniolo et al. [10], with a sample of 51 students of an APAE of São Carlos, with ID of unclear etiology, 13 cases were found in which it was possible to establish the ID etiology. 2 had a clinical history suggesting X-linked ID, and in 36 the etiology was not confirmed.

Research in Human and/or Clinical Cytogenetics in the capital of Amazonas state is still fairly scarce and there are a limited number of laboratories with the specific service of karyotype analysis in the public sectors, with this type of service being uncommon even in the private sector. This prevents access to the most common clinical diagnostic service for individuals with non-Down syndrome ID, including cytogenetic analysis (karyotype evaluation) and its possible association or not with any chromosomal alterations.

\section{Material and Methods}

This study was approved by the Research Ethics Committee of the State University of Amazonas under authorization number CEP-UEA 1.475 .898 and that written informed consent was obtained from all participants.

\subsection{Sample}

Individuals with non-Down syndrome intellectual disabilities attending the Ilza Garcia Pedagogical Partner Service Center-APAE/Manaus, were included. Out of a population composed of 61 individuals eligible for inclusion in the sample, only 31 were included, these being 20 females and 11 males, aged 9 to 53 years.

All the parents or guardians signed a consent form and then underwent a diagnostic-clinical screening conducted through a questionnaire in the form of Diagnostic Form, in which each individual received an identification code (APAE-01 to APAE-31) and data related to personal aspects, illness history, pregnancy, childbirth, consanguinity and dysmorphism were collected. The medical records of the individuals were also analyzed for verification of the psychological or 
neurological screening which indicated the degree of ID of these individuals. These data were tabulated and analyzed using the Excel $2016^{\circledR}$ program.

\subsection{Karyotype Collection, Culture and Analysis}

Blood sample of $5 \mathrm{~mL}$ was collected from each individual by trained healthcare professionals. The lymphocyte culture was performed according to the technique of Moorhead et al. [11], with alterations. Each $5 \mathrm{~mL}$ sample of blood was transferred to two duly identified heparinized tubes and placed in a vertical position at room temperature in the sterile laminar flow cabinet. Next, $500 \mu \mathrm{L}$ of whole peripheral blood were placed in complete culture medium composed of $8 \mathrm{~mL}$ of RPMI 1640 (Gibco/Invitrogen ref. 22400-089); 2 $\mathrm{mL}$ Fetal Bovine Serum (Gibco/Invitrogen ref. 1600-044); $200 \mu \mathrm{L}$ of L-Glutamine (Gibco/Invitrogen ref. 21051-024) to $0.03 \% ; 200 \mu \mathrm{L}$ of Phytohemagglutinin (Gibco/Invitrogen ref.10576-015); and $10 \mu \mathrm{L}$ of Antibiotic + Antimycotic (100X) (Gibco/Invitrogen ref.15240-096). The culture was then incubated for $72 \mathrm{~h}$ in an incubator at $37^{\circ} \mathrm{C}$. Fifty minutes before completing the $72 \mathrm{~h}$ incubation of the culture, $60 \mu \mathrm{L}$ of Colcemide ${ }^{\circledR}$ (Gibco/Invitrogen ref.15212-012) was added. Upon completing the $72 \mathrm{~h}$, the material was removed from the incubator for processing of the cultures. For hypotonization, a 0.075 $\mathrm{M}$ solution of $\mathrm{KCl}$ was added to the culture, in $1 \mathrm{~mL}$ additions to a final volume of $10 \mathrm{~mL}$, with homogenization after each addition. Fixation was performed with methanol (Merck) and acetic acid (Merck) at a ratio of 3:1. For the extension of the material, it was dropped on washed slides, kept in cold water for injection, passed twice over a flame and racked for air drying.

For the chromosome analysis the $\mathrm{G}$ banding technique [12] with modifications was used. The karyotype analysis was performed using a NIKON Eclipse E200 light microscope, with an average 20 to 30 metaphases per individual observed, in cases of suspected mosaicism this number increased to 50 . Next, image capturing and assembly of karyotypes were performed, using the GeneAll-HD software, and the results evaluated according to the standards of the International System for Human Cytogenetic Nomenclature [13].

\section{Results}

In 2015 the Ilza Garcia Pedagogical Partner Service Center-APAE/Manaus attended 61 individuals with non-Down syndrome ID, whose ages ranged from 09 to 53 years, without defined clinical diagnosis, being eligible for this study, of these, 31 (51.67\%) composed the sample after signing the consent form.

\subsection{Analysis of Diagnostic-Clinical Data}

Females were more prevalent in the sample, accounting for $64.52 \%$ (20/31) of the individuals, with a ratio of 1.8:1 compared to the males. The mean age was 31.29 years [standard deviation (SD): (11.45)], with a median of 29 (9-53) years.

When asked about the pre- and perinatal history, 9.67\% (3/31) of the parents confirmed exposure to teratogens or abortifacients, such as alcohol, drugs, tobacco and oxytocin. Perinatal data showed that the majority of the patients were born at full-term $[74.2 \%$ (23/31)], followed by pre-term [12.9\% (4/31)] and post-term [12.9\% (4/31)]. In $87.1 \%(27 / 31)$ of the reports vaginal type birth was indicated, with cesarean delivery having occurred in $12.9 \%$ (4/31) of the cases.

Regarding family history, parental consanguinity was denied by $83.87 \%$ (26/31) of the patients; $3(9.67 \%)$ confirmed consanguinity; 1 (3.23\%) could not provide the data due to adoption into the family; and 1 (3.23\%) did not answer. Other cases of ID in the family were reported by $61.29 \%$ (19/31) of the subjects. Regarding the outpatient clinical examination for the detection and classification of the ID, it was verified that 13 (41.94\%) had been performed by a neurologist, 13 (41.94\%) by a neurologist and a psychologist, $2(6.45 \%)$ by a psychologist and $3(9.67 \%)$ had no evaluation (Table 1). Of these, the only ones that underwent an IQ 
Table 1 Frequency of diagnostic evaluation of ID by a qualified professional and occurrence of IQ test.

\begin{tabular}{lll}
\hline Professional & N & $\%$ \\
\hline Neurologist & 13 & 41.94 \\
Psychologist & 2 & 6.45 \\
Neurologist and psychologist & 13 & 41.94 \\
No evaluation & 3 & 9.67 \\
Application of IQ test & & \\
With IQ test & 2 & 6.45 \\
Without IQ test & 28 & 93.55 \\
\hline
\end{tabular}

$\mathrm{N}$-number of individuals.

Table 2 Frequency of ID classification attributed by a professional of the area.

\begin{tabular}{lll}
\hline ID classification & N & $\%$ \\
\hline Mild ID & 8 & 25.8 \\
Moderate ID & 8 & 25.8 \\
Severe ID & 2 & 6.45 \\
Unspecified ID & 13 & 41.94 \\
\hline
\end{tabular}

$\mathrm{N}$-number of individuals.

Table 3 Distribution of the cases studied, according to the presence of at least one dysmorphism by body segment.

\begin{tabular}{lll}
\hline Body segment & $\mathrm{N}(\%)$ & Most common dimorphism by body segment \\
\hline Cephalic (skull + face) & $16(51.6)$ & $\begin{array}{l}\text { Elongated face, broad brow, microcephaly, macrocephaly, facial asymmetry, dysgnathia, } \\
\text { prognathism, micrognathia, macrognathia, ogival palate, low-set ears, simplified ears, } \\
\text { orbital hypo and hypertelorism. }\end{array}$ \\
Chest & $5(16.1)$ & $\begin{array}{l}\text { Winged scapula, scoliosis, lordosis. } \\
\text { Upper Limbs }\end{array}$ \\
Lower members & $4(22.6)$ & Camptodactyly, clinodactyly, small hands. \\
\hline
\end{tabular}

Most common dimorphism founded in each body segment in the cases studied.

Table 4 Cases of chromosome abnormalities detected by classical cytogenetics.

\begin{tabular}{llll}
\hline Syndrome & Chromosomal abnormalities & Karyotype & No. of cases \\
\hline Turner & Mosaic & $45, \mathrm{X} / 46, \mathrm{XX}$ & 1 \\
& Heterochromatic variation & $46, \mathrm{XY}, 9 \mathrm{qh}+$ & 1 \\
\hline
\end{tabular}

Cases APAE-09 and APAE-17.

test were the 2 that had been evaluated only by a psychologist. However, the ID verified had been classified by professionals as Mild (25.8\%), Moderate (25.8\%) Severe (6.45\%) and Unspecified (41.94\%), as presented in Table 2.

In the physical examination, it was found that $83.87 \%$ (26/31) of the probands presented at least one dysmorphological change. Two did not perform the physical examination, representing $6.45 \%$, and three (9.67\%) presented isolated ID. The absolute number and frequency of the subjects who had at least one change in body segment are presented in Table 3 , as is the list of the most common dysmorphisms. The head segment was the most affected (51.6\%), with the most frequent findings being: elongated face, broad brow, microcephaly, macrocephaly, facial asymmetry, dysgnathia, prognathism, micrognathia, macrognathia, ogival palate, low-set ears, simplified ears, orbital hypo and hypertelorism.

\subsection{Cytogenetic Analysis}

The karyotype analysis was performed on all samples, among which 2 (6.45\%) presented abnormal tests (Table 4). The clinical manifestations of the 

with Non-down Syndrome Intellectual Disability

chromosome abnormalities detected by classical cytogenetics, for each individual, are described below.

Case APAE-09, male subject, 28 years of age, classified as having non-specified ID, in the physical examination presented wide forehead, pointed chin, orbital hypotelorism and strabismus; nose with broad base, low bridge and downward pointing tip; simplified ears; upper limb: dysgnathia, clinodactyly of the 5th finger. The chromosomal alteration detected was 46 ,
$\mathrm{XY}, 9 \mathrm{qh}+$ (Figs. 1 and 2).

Case APAE-17, female subject, 46 years of age, classified as having moderate ID, in the physical examination presented large nose with elongated base, camptodactyly, winged scapula and short stature. The karyotype analysis revealed the change $45, \mathrm{X} / 46$, $\mathrm{XX}$ (Figs. 3 and 4) equating to mosaic Turner syndrome in the proportion of $10 \%$ in 50 metaphases analyzed.

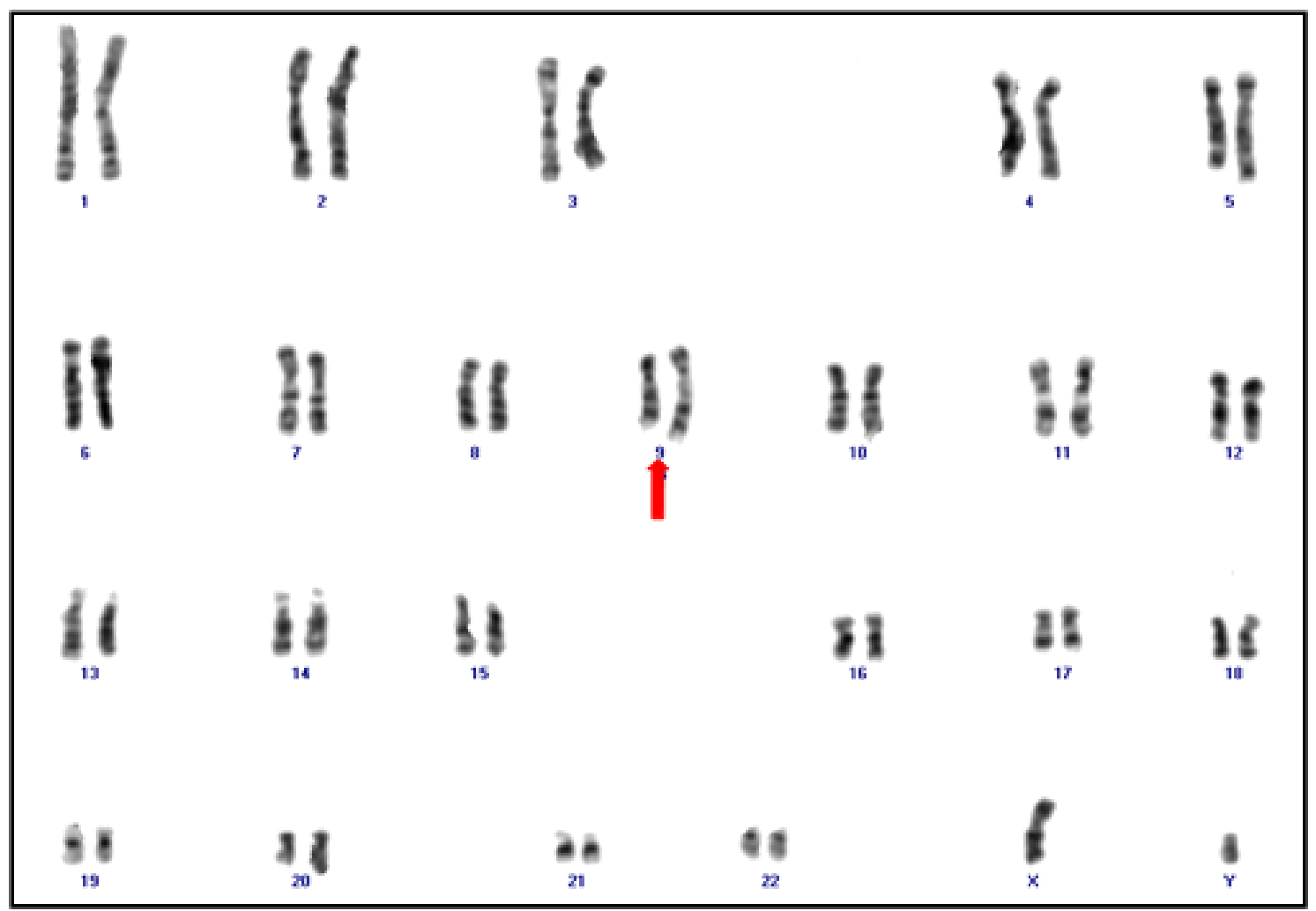

Fig. 1 Karyotype of case APAE-09, 46, XY, 9qh+.

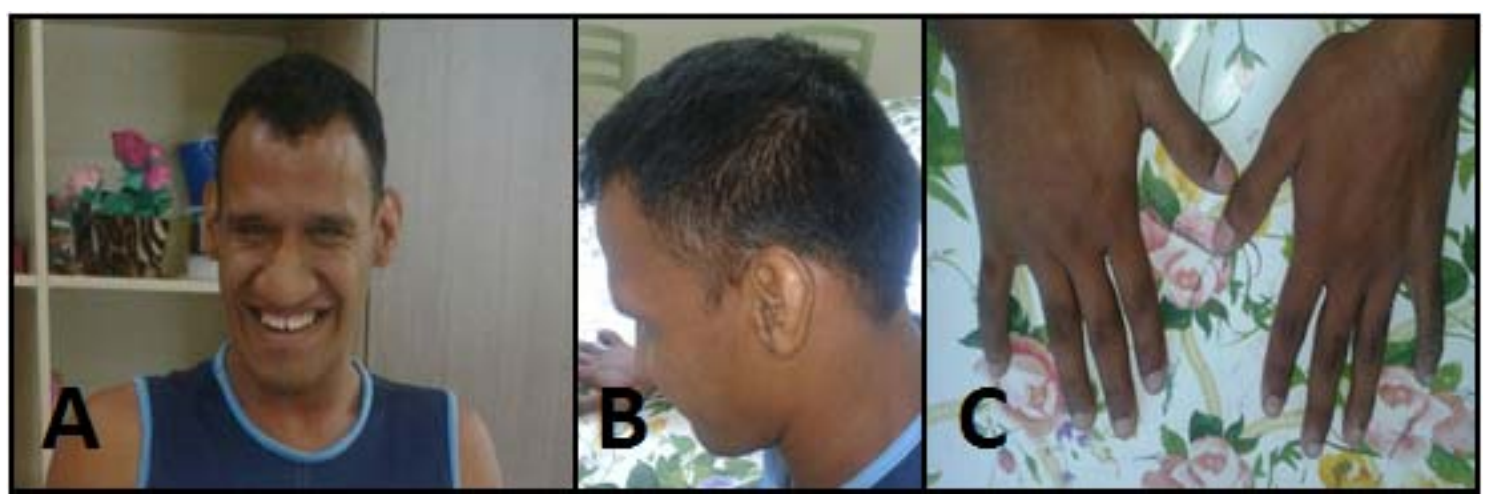

Fig. 2 Dysmorphic features found in case APAE-09. A: Wide forehead, pointed chin, orbital hypotelorism and strabismus; nose with broad base, low bridge and downward pointing tip; B: Simplified ears; C: Clinodactyly of the 5th finger. 

with Non-down Syndrome Intellectual Disability

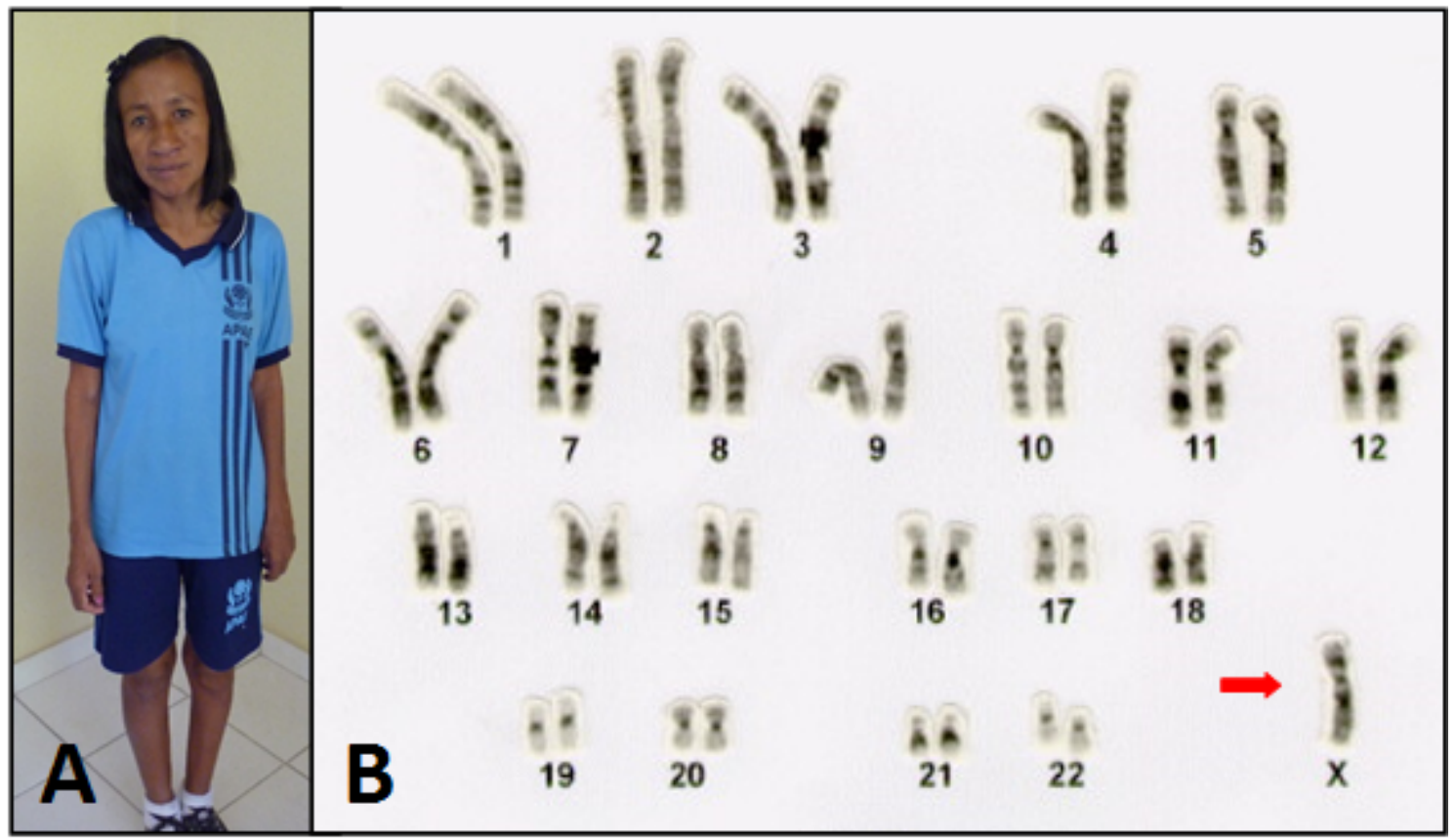

Fig. 3 A, Case APAE-17, female subject, 46 years of age, classified as having moderate ID. B, Karyotype characteristic of Turner syndrome, monosomy of the sexual chromosome $(45, \mathrm{X})$.

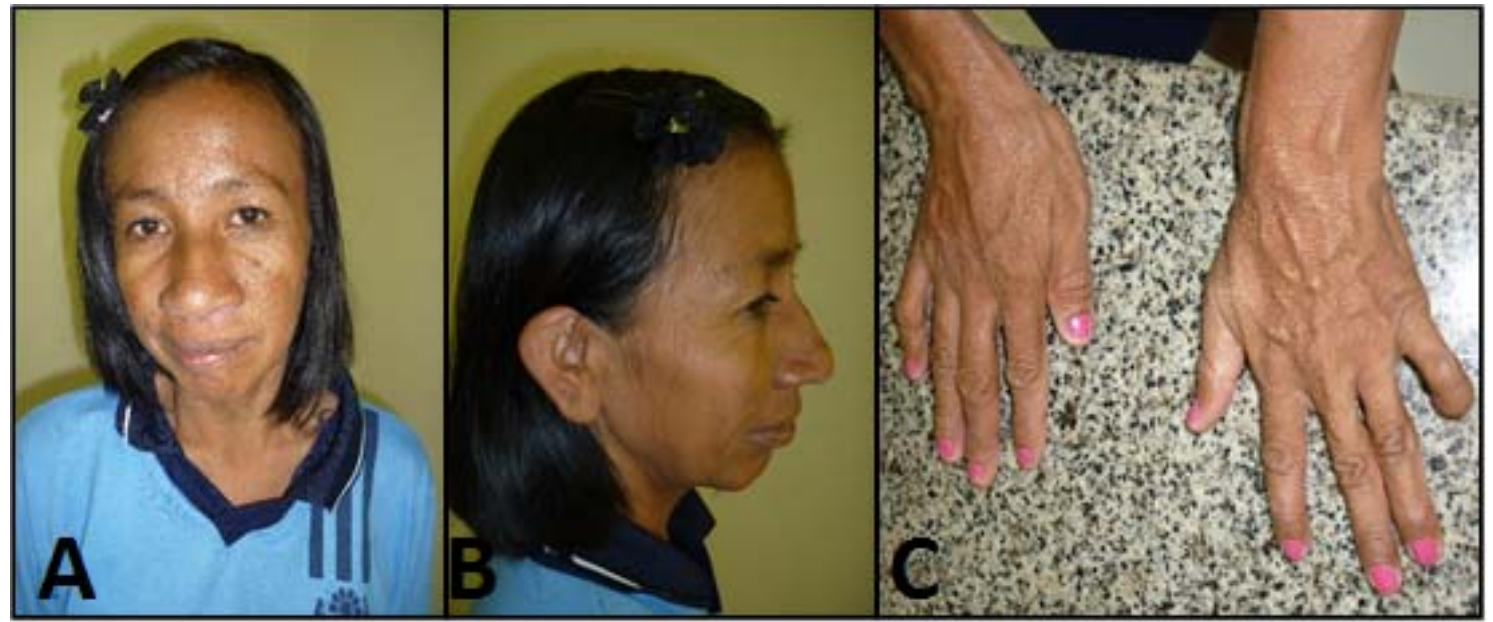

Fig. 4 Dysmorphic features found in case APAE-17. A, large nose with elongated base. B, Simplified ears. C Camptodactyly.

\section{Discussion}

In this study the frequency distribution according to the gender of the patients showed a predominance of females in relation to males, in the ratio of $1.8: 1$, which is not in agreement with the proportions described in the literature, both in studies related to genetic changes in general [14] and those, such as the study by Storniolo et al. [10], in which the sample was composed of students of an APAE in San Carlos with ID. In the literature the male prevalence is mainly due to the large amount of $\mathrm{X}$-linked conditions that occur with ID, as the male genome is more vulnerable to mutations in this chromosome due to the absence of an allele [15]. This discrepancy can be attributed to the sample in this study not including individuals with Down syndrome, who are the majority in the study institution.

It is known that the diagnosis of ID can only be made in people over 5 years of age, whose IQ can be tested [16], and depends on the presence of cognitive performance below the mean associated with adaptive 
deficits, with demonstration prior to 18 years of age [17]. People under the age of 5 are classified as having DNPD (delayed neuropsychomotor development). In this study, it could be inferred that the professionals mainly focused on the clinical examination, as only three subjects had performed the IQ test. The others were classified according to what the professional had measured in the outpatient clinic and confirmed in the medical record, a very common practice in health centers and similar institutions. Following this reasoning, the ID in this study were classified as follows: $41.94 \%$ could not be specified, $25.8 \%$ were classified as mild, $25.8 \%$ moderate and $6.45 \%$ severe. These results differed from the findings of Storniolo et al. [10], which showed a predominance of patients with moderate ID $(54.90 \%)$, followed by severe ID (21.57\%).

In the study sample there was a high prevalence of cases of ID associated with physical alterations, a characteristic indicated in the literature as syndromic ID [5]. Facial changes were the most frequent among the patients, highlighting the detailed observation of the syndrome characteristics, as facial dysmorphism contributes more to the diagnosis of syndromes previously described in the literature $[18,19]$.

The presence of parental consanguinity was denied in the majority of cases, as was family history of neuropsychiatric impairment. Familial recurrence associated with cases of moderate to severe ID is reported in the literature [20], with the description of families with many affected individuals being unusual, with this occurring more often in conditions linked to the $\mathrm{X}$ chromosome [21]. For idiopathic ID, positive family history is described in $3 \%$ to $7 \%$ of cases [22].

Karyotype examination is recommended as a first step in the laboratory investigation of cases of ID [23, 24]. A systematic review [19] demonstrated that, in various studies, chromosomal abnormalities were found, on average, in $10 \%$ of the patients analyzed. In this study the percentage of cases showing some kind of chromosomal abnormality found was $6.45 \%$. This may also be due to the specificity of the sample in question, considering the non-inclusion of individuals with Down syndrome, as compared to the study by Abreu [9], performed in three APAES of the Rio Preto region of São Paul, where $12.1 \%$ of the individuals with ID presented chromosomal abnormalities and of these $90.2 \%$ were numerical, with a higher prevalence of trisomy 21 , observed in $77.2 \%$ of the cases.

The presence of large numbers of findings in the dysmorphological examination $(>6)$ is described in association with chromosomal alterations [16], a fact confirmed in the case of mosaicism detected in this study. However, many of the patients whose karyotype study was normal also presented more than six dysmorphisms, suggesting further investigation for these individuals with complementary examinations using molecular cytogenetic techniques.

Regarding the changes found, only case APAE-17 would be considered to have chromosomal alteration in the literature, because the karyotype found indicated mosaic Turner syndrome, a chromosomal alteration where there is only one functional $\mathrm{X}$ chromosome. The chromosome constitution found was 45, X. According to the literature, Turner syndrome presents an incidence of $1 / 2500$ in females [25-27]. Some dysmorphological characteristics compose the phenotype, such as short and webbed neck, hair low-set on the neck, shield chest, short stature, etc. and patients may also have hearing problems, visual disturbances, learning disabilities and infertility, among other renal and cardiac disorders $[26,27]$. In case APAE-17 the dysmorphological findings were consistent with certain aspects of the phenotype described in the literature, as the subject presented a short and webbed neck, short stature and learning difficulties. This syndrome presents great phenotypic variability and may manifest as the most classical form, in which dysmorphisms are clearly evident, to form with few signs of dysmorphism, with the latter making the prognosis difficult [28]. In the case of mosaicism, the literature cites two types, $\mathrm{XX} / \mathrm{X} 0$ and $\mathrm{XXY} / \mathrm{X} 0$, 
however, in cases of $\mathrm{XX} / \mathrm{X} 0$ the dysmorphic characteristics for Turner syndrome are attenuated [29-31]. In the case found in this study, as well as the mosaicism being $\mathrm{XX} / \mathrm{X} 0$, the cellular proportion of mosaic cells was $10 \%$, which explains the phenotype presenting the dysmorphisms characteristic of this syndrome in attenuated form.

Regarding case APAE-09, the change found is actually what the majority of the references consider common cases of variation of heterochromatin in normal karyotypes [32, 33], i.e. not representing major problems for the individuals. However, there are studies mentioning individuals with increased heterochromatin of chromosome $9(9 q h+)$, as in the case found, presenting a higher risk of a chromosomally abnormal conception [34], others suggest that the difference between homologous pairs could hamper pairing or non-disjunction predisposing carriers of heteromorphism to the development of intellectual disabilities among others [33]. This suggests the need for further investigation.

\section{Conclusions}

In this study, it was possible to perceive the great variability of presentation of intellectual disability. The sample consisted of cases of diverse levels of severity of ID and various patterns of syndromic impairment. This was not greater due to the first inclusion factor, to not present Down syndrome, in an institution in which the majority of the patients belong to this class, as well as some that fulfilled the inclusion criteria, however, did not wish to participate. This same factor may have contributed to the higher prevalence of ID cases in women in this study, unlike other studies. The disparity in the ages of the probands was mainly due to the fact that the majority consisted of people who had been in the institution for a long time, with some newcomers in the youth age group.

The dysmorphisms found were important to guide the investigation, suggesting a prior hypothetical diagnosis for each case.
The $\mathrm{G}$ banding technique was successful, enabling the detection of mosaicism and heterochromatin variants. The low number of changes found suggests, for these cases, the existence of other aspects, besides genetic factors, as a cause of ID or that there were changes not detectable by the technique employed, requiring additional tests including the use of molecular techniques for the individuals whose dysmorphological phenotypes indicate some type of syndrome.

\section{References}

[1] American Association on Intellectual and Developmental Disabilities. Accessed April 20, 2016. https://aaidd.org/.

[2] Linhares, N., Svartman, M., and Valadares, E. 2012. "Diagnóstico citogenético de pacientes com retardo mental idiopático.” J. Bras Patol Med Lab 48: 33-9.

[3] World Health Organization. 2004. International Statistical Classification of Diseases and Related Health Problems (2nd ed.). Geneva: World Health Organization.

[4] Carvalho, E. N. S., and Maciel, D. M. A. 2002. "Nova concepção de deficiência mental segundo a American Association on Mental Retardation-AAMR: sistema 2002.” Temas em Psicologia da SBP 11: 147-56.

[5] Rocha, N. 2014. "Busca de microrrearranjos no cromossomo X em meninos com deficiência intellectual.” Master’s thesis. Brasília: Programa de Pós-Graduação em Ciências da Saúde.

[6] Inlow, J. K., and Restifo, L. L. 2004. "Molecular and Comparative Genetics of Mental Retardation.” Genetics 166 (2): 835-81.

[7] Della-Rosa, V. A., Moraes, A. M. S. M., Gambarini, G. H. R., and Mariucci, R. G. 2004. "Oito Anos de Citogenética Clínica na Universidade Estadual de Maringá: Integrando Ensino e Pesquisa.” Crongresso Brasileiro de Extensão Universitária, 12-15.

[8] Alliende, M. A., Cámpora, L., Curotto, B., Toro, J., Valiente, A., Castillo, M., et al. 2008. "Búsqueda de afecciones genéticas como etiología de déficit intelectual en individuos que asisten a escuelas de educación especial.” Rev Méd Chile 136: 1542-51.

[9] Abreu, L. S. 2009. "Estudo citogenético de indivíduos afetados por Deficiência Mental em três APAES da região de Rio Preto.” Master's thesis. São Paulo: Programa de Pós-Graduação em Genética da Universidade de São Paulo.

[10] Storniolo, L. M. A., Gimenes, P. V. S., Costa, A. R., and Melo, D. G. 2011. “Aconselhamento genético de famílias de pacientes com deficiência intelectual da APAE de São 
Carlos, São Paulo, Brasil.” Cad. Saúde Colet 19: 375-83.

[11] Moorhead, P. S., Nowell, P. C., Mellmam, W. J., Battips, D. M., and Hungerford, D. A. 1960. "Chromosome Preparations of Leukocytes Cultured from Human Peripheral Blood.” Expi Cell Res 20: 613-6.

[12] Seabright, M. 1971. "A Rapid Banding Technique for Human Chromosomes.” Lancet 2: 971-2.

[13] Shaffer, L. G., McGowan-Jordan, J., and Schmid, M. 2013. An International System for Human Cytogenetic Nomenclature-Recommendations of the International Standing Committee on Human Cytogenetic Nomenclature Published in collaboration with "Cytogenetic and Genome Research” (1st ed.). Basel: Karger.

[14] Vasconcelos, M. M. 2004. "Retardo Mental.” J de Pediatria 80: 71-82.

[15] Lubs, H. A., Stevenson, R. E., and Schwartz, C. E. 2012. "Fragile $\mathrm{X}$ and $\mathrm{X}$-linked Intellectual Disability Four Decades of Discovery.” Am J Hum Genet 90: 579-90. doi: 10.1016/j.ajhg.2012.02.018.

[16] Moeschler, J. B., and Shevell, M. 2006. “Clinical Genetic Evaluation of the Child with Mental Retardation or Developmental Delays.” Pediatrics 17: 2304-16.

[17] AAP (Associação Americana de Psiquiatria). Manual Diagnóstico e Estatístico de Transtornos Mentais. AAP; 1994.

[18] Curry, C. J., Stevenson, R. E., Aughton, D., Byrne, J., Carey, J. C., Cassidy, S., et al. 1997. "Evaluation of Mental Retardation: Recommendation of a Consensus.” Am J Med Genet 72: 468-77.

[19] van Karnebeek, C. D., Jansweijer, M. C., Leenders, A. G., Offringa, M., Hennekam, R. C. 2005. "Diagnostic Investigations in Individuals with Mental Retardation: A Systematic Literature Review of Their Usefulness.” Eur J Hum Genet 13: 6-25. doi: 10.1038/sj.ejhg.5201279.

[20] Ellison, J. W., Rosenfeld, J. A., and Shaffer, L. G. 2012. “Genetic Basis of Intellectual Disability.” Annu Rev Med 64: 1-10. doi: 10.1146/annurev-med-042711-140053.

[21] Topper, S., Ober, C., and Das, S. 2011. "Exome Sequencing and the Genetic of Intellectual Disability.” Clin Genet 80: 117-26. doi: 10.1111/j.1399-0004.2011.01720.x.

[22] Edelmann, L., and Hirschhorm, K. 2009. "Clinical Utility of Array CGH for the Detection of Chromosomal Imbalances Associated with Mental Retardation and Multiple Congenital Anomalies.” Ann N Y Acad Sci 1151: 157-66. doi: 10.1111/j.1749-6632.2008.03610.x.

[23] Wolsteholme, J. 1992. "An Introduction to Human Chromosome and Their Analysis." In Human Cytogenetics-Constitucional Analysis: A Practical Approach, edited by Rooney, D. E., and Czepulkowski,
B. H.

[24] Linhares, N. D., SvartmanII, M., and Valadares, E. R. 2012. "Diagnóstico citogenético de pacientes com retardo mental idiopático.” J Bras Patol Med Lab 48: 33-39. doi: 10.1590/S1676-24442012000100007.

[25] Chvatal, V. L. S., Böttcher-Luiz, F., and Turato, E. R. 2009. "Respostas ao adoecimento: mecanismos de defesa utilizados por mulheres com Síndrome de Turner e variantes.” Ver Psiq Clin 36: 43-47. doi: 10.1590/S0101-60832009000200001.

[26] Jung, M. P., Cardoso, M. H. C. A., Villar, M. A. M., and Llerena, J. C. 2009. "Revisitando o desvendamento da etiologia da Síndrome de Turner." Hist. cienc. saude-Manguinhos 16: 361-76. doi: 10.1590/S0104-59702009000200005.

[27] Santos, V., Marçal, M., Amaral, D., Pina, R., Lopes, L., and Fonseca, G. 2010. "Turner Syndrome from Child to Adult: A Multidisciplinary Approach.” Acta Med Port 23: 873-82.

[28] Carvalho, A. B., Guerra-Junior, G., Baptista, M. T., Marques-de-Faria, A. P., Lemos-Marini, S. H., and Maciel-Guerra, A. T. 2010. "Turner Syndrome: A Pediatric Diagnosis Frequently Made by Non-pediatricians.” J Pediatr (Rio J) 86: 121-5. doi: 10.1590/S0021-75572010000200007.

[29] Lippe, B. M. 2008. “Turner Syndrome.” In Pediatric Endocrinology (3rd ed.), edited by Sperling, M. Philadelphia: Saunders, 1-387.

[30] Wyss, D., DeLozier, C. D., Daniell, J., and Engel, E. 1982. "Structural Anomalies of the X Chromosome: Personal Observation and Review of Non-mosaic Cases." Clin Genet 21: 145-59.

[31] Rao, E., Weiss, B., Fukami, M., Rump, A., Niesler, B., Mertz, A., et al. 1997. "Pseudoautosomal Deletions Encompassing a Novel Homeobox Gene Cause Growth Failure in Idiopathic Short Stature and Turner's Syndrome.” Nat Genet 16: 54-63.

[32] John, B. 1998. “The Biology of Heterochromatin.” In Heterochromatin Molecular and Structural Aspects, edited by Verma, R. S. New York: Cambridge University Press, 74-128.

[33] Colombo, J., Fett-Conte, A. C., and Silva, A. E. 2000. "Polimorfismo cromossômicos das regiões de heterocromatina constitutiva e organizadora do nucléolo em distúrbios autísticos e síndrome de down.” HB Cient 7: 15-27.

[34] Kosyakova, N., Grigorian, A., Liehr, T., Manvelyan, M., Simonyan, I., Mkrtchyan, H., et al. 2013. "Heteromorphic Variants of Chromosome 9.” Mol Cytogenet 6: 14. doi: 10.1186/1755-8166-6-14. 